\title{
The durability of sitagliptin in elderly patients with type 2 diabetes
}

This article was published in the following Dove Press journal:

Clinical Interventions in Aging

7 November 2014

Number of times this article has been viewed

\author{
Ching-Jung Hsieh \\ Feng-Chih Shen
}

Division of Endocrinology and Metabolism, Department of Internal Medicine, Kaohsiung Chang Gung Memorial Hospital and Chang Gung University College of Medicine, Kaohsiung, Taiwan
Correspondence: Ching-Jung Hsieh Department of Internal Medicine, Kaohsiung Chang Gung Memorial Hospital, I23, Ta-Pei Road, Niao-Sung District, Kaohsiung City 83305, Taiwan Tel +886 773 I7l 23, ext 8302 Fax +88677322402 Email c2607c@ms56.hinet.net
Aim: To evaluate the durability of sitagliptin and to assess changes in clinical chronic complications following sitagliptin monotherapy for 48 months in elderly patients with type 2 diabetes mellitus (T2DM).

Subjects and methods: We enrolled 76 drug-naïve patients (40 women and 36 men; mean age: $71.3 \pm 11.7$ years) with T2DM who received $25-100 \mathrm{mg}$ of sitagliptin therapy from an outpatient clinic. The observational period for each patient was $>48$ months, beginning at the time sitagliptin therapy was initiated. The following were measured or performed at the beginning of each year: body mass index; serum total cholesterol, low-density lipoprotein, high-density lipoprotein; triglyceride levels; creatinine $(\mathrm{Cr})$ levels; urine albumin and urine $\mathrm{Cr}$; nonmydriatic fundusgraphy; and semiquantified neuropathy. The fasting plasma glucose and glycated hemoglobin $\left(\mathrm{HbA}_{1 \mathrm{c}}\right)$ was measured every 3-6 months.

Results: The change in $\mathrm{HbA}_{1 \mathrm{c}}$ was significantly reduced after 6 months of therapy $(7.1 \% \pm 0.8 \%$ to $6.3 \% \pm 0.2 \%$ ). No changes in fasting plasma glucose, $\mathrm{Cr}$, serum total cholesterol, triglyceride, low-density lipoprotein, high-density lipoprotein, body mass index, and microvascular complications were apparent. Using repeated measures to test the sequential changes in $\mathrm{HbA}_{1 \mathrm{c}}$ from month 6 to month 48, the test of within-subjects effect was not significant $(P=0.34)$.

Conclusion: Sitagliptin has a durable effect and stabilizes microvascular complication progression in elderly patients. This study can provide useful data for clinicians and health care professionals using sitagliptin monotherapy in the treatment of elderly patients with T2DM.

Keywords: type 2 diabetes mellitus, sitagliptin, oral antidiabetic drugs, dipeptidyl peptidase IV inhibitor

\section{Introduction}

Type 2 diabetes mellitus (T2DM) is a progressive disease due to the gradual dysfunction of pancreatic $\beta$-cells. ${ }^{1}$ A single oral antidiabetic drug (OAD) for blood glucose control in patients with T2DM has a 50\% failure rate after 3 years and a 75\% failure rate after 9 years. ${ }^{1}$ In clinical practice, the ideal OAD should have the following effects: efficacy; no weight gain; no risk of hypoglycemia; no risk of cardiovascular events; and preserving pancreatic $\beta$-cells. In the elderly, the risks of renal insufficiency and hypoglycemia are higher than in younger patients with T2DM. There are limited data regarding the use of pharmacologic agents in elderly patients with T2DM. According to the recommendation of American Diabetic Association and European Association for the Study of Diabetes, dipeptidyl peptidase IV (DPP-4) inhibitors have an intermediate effect on patients with T2DM, a lower risk of hypoglycemia, a lower risk of weight gain, and fewer side effects than other OADs and insulin. ${ }^{2}$ No increase in cardiovascular events has been associated with DPP-4 inhibitors based on two recent large clinical trials., 
The mechanism of action of DPP-4 inhibitors involves augmentation of the incretin axis by increasing endogenous glucagon-like peptide-1 (GLP-1) and glucose-dependent insulinotropic peptide active form concentrations, both of which result in the stimulation of glucose-dependent insulin and the inhibition of glucagon; thus, a reduction in blood glucose follows. ${ }^{5-7}$ When compared with other established OADs in several randomized controlled trials, ${ }^{8-12}$ sitagliptin demonstrated noninferiority in efficacy endpoints. In addition to metformin, sulfonylurea (SU) is another popular OAD based on a Taiwanese study. ${ }^{13} \mathrm{SU}$, which directly stimulates pancreatic $\beta$-cells for insulin secretion, leads to earlier $\beta$-cell exhaustion. The thiazolidinediones can improve insulin resistance and durability in glycemic control, but they may lead to an increased risk of cardiovascular events and bladder cancer. ${ }^{14-16}$ Heart function is less in the elderly than in young adults; the risk for cancer is also high in the elderly. Metformin-induced lactic acidosis is also a concern. Sitagliptin was the first DPP-4 inhibitor used to control blood glucose in Taiwan. A previous meta-analysis confirmed the safety of sitagliptin in elderly patients with T2DM. ${ }^{17}$ According to a previous study, sitagliptin decreases $\beta$-cell apoptosis and is associated with a decrease of $\beta$-cell function deterioration. ${ }^{18}$ In human studies, however, the durability of sitagliptin is seldom mentioned. In all studies involving sitagliptin as monotherapy, the duration of treatment was $<1$ year. ${ }^{5,7}$ In the current study, we observed the blood glucose changes after monotherapy sitagliptin was used for 48 months in elderly patients with T2DM; we also evaluated the durability of sitagliptin and chronic complications.

\section{Subjects and methods Subjects}

There were 76 patients with T2DM (40 women and 36 men; mean age: $71.3 \pm 11.7$ years) who were first diagnosed and had participated in a diabetic share-care education program for $>6$ months. All of the patients were $>65$ years of age and had never received medical treatment before enrollment in the diabetes education program and study. The patients received a diabetic diet and share-care education every 3 months since T2DM was diagnosed, and sitagliptin monotherapy was prescribed. The inclusion criteria limited the study subjects to outpatients with T2DM from our Metabolism and Endocrinology Clinic who were treated with sitagliptin for diabetic control. The exclusion criteria included the following: type 1 diabetes mellitus; treatment with other antidiabetic agents; diabetes secondary to other causes, such as surgery, pharmaceutical products, malnutrition, and infections; and participation in a clinical trial or other clinical study during the index period. The case identification period or index period was defined as the time between January 1, 2009 and January 30, 2010. The observational period for each patient was $>48$ months, beginning at the time that sitagliptin monotherapy was started. The dose of sitagliptin was based on the initial estimated glomerular filtration rate (eGFR), as follows: $100 \mathrm{mg}$ /day for patients with an eGFR $\geq 50 \mathrm{~mL} /$ minute $/ 1.73 \mathrm{~m}^{2} ; 50 \mathrm{mg} /$ day for patients with an eGFR $\geq 25 \mathrm{~mL} /$ minute $/ 1.73 \mathrm{~m}^{2}$ but $<50 \mathrm{~mL} /$ minute $/ 1.73 \mathrm{~m}^{2} 50 \mathrm{mg} /$ day; and $25 \mathrm{mg} /$ day for patients with an eGFR $<25 \mathrm{~mL} /$ minute $/ 1.73 \mathrm{~m}^{2}$.

\section{Methods}

Among this continuous sitagliptin user cohort, the following clinical and laboratory parameters were measured at baseline and every year thereafter: any self-reported hypoglycemia symptoms; body mass index; nonmydriatic fundusgraphy; semiquantification of neuropathy; serum levels of total cholesterol (TC), low-density lipoprotein (LDL), highdensity lipoprotein (HDL), triglycerides (TG), and creatinine $(\mathrm{Cr})$; and urine albumin and urine $\mathrm{Cr}$. The blood lipid profile, including TC, LDL, HDL, and TG, were checked after fasting for $>10$ hours. The comorbidity (dyslipidemia and hypertension) and chronic complications of T2DM at baseline and before the last follow-up evaluation were collected and analyzed. The glycated hemoglobin $\left(\mathrm{HbA}_{1 c}\right)$ and fasting plasma glucose (FPG) levels were measured every 3-6 months in each patient. Protective sensation was assessed using a 5.07 Semmes-Weinstein (SW) nylon filament test (10 $\mathrm{g}$ monofilament) and vibration perception using $128 \mathrm{~Hz}$ Rydel Seiffer forks. Two observers confirmed all measurements. Neuropathy was evaluated based on the vibration perception threshold of the great toe and internal malleolus bilaterally. The patients were asked to indicate when the vibration sensation was lost. The vibration was determined on a 9-point grading scale $(0 / 8-8 / 8)$ of a tuning fork. Patients were diagnosed with neuropathy if the vibration perception threshold was $\leq 4$ on an 8-point scale. ${ }^{19}$ The vibration perception threshold yielded a sensitivity of $86 \%$ and a specificity of $76 \%{ }^{20}$

Two examiners conducted the SW monofilament test when patients were unable to observe their feet. The $10 \mathrm{~g} \mathrm{SW}$ monofilament was used on ten sites of the foot, as follows: dorsal surface of the foot between the base of the first and second toes; the first, third, and fifth toes; the first, third, 
and fifth metatarsal heads; the medial and lateral midfoot; and the heel. The SW monofilament was pressed on the test site with enough pressure to bend the monofilament for 1 second. Patients were asked to answer "Yes" or "No" when they felt or did not feel the touch of the monofilament, respectively. If a patient did not feel the filament at $>4$ sites, neuropathy was diagnosed. The sensitivity and specificity at ten sites with a $10 \mathrm{~g} \mathrm{SW}$ monofilament was $93.1 \%$ and $100 \%$, respectively. ${ }^{21}$

Nonmydriatic retinal photography was performed using a CR6-45NM nonmydriatic retinal camera (Canon Inc., Tokyo, Japan) by two examiners. Retinopathy was diagnosed according to the American Academy of Ophthalmology Retina/Vitreous Panel (Preferred Practice Patterns Committee) and confirmed by one ophthalmologist. ${ }^{22}$ The effectiveness of the nonmydriatic retinal camera in the diagnosis of retinal disease has a sensitivity of $92 \%$ and a specificity of $96 \%{ }^{23}$ Nephropathy was defined as an increase in urine albumin/urine $\mathrm{Cr}>30 \mathrm{mg} / \mathrm{dL}$ in the first morning urine. ${ }^{24}$ The abbreviated Modification of Diet in Renal Disease (MDRD) Study Group equation was used to calculate the eGFR (mL/minute $/ 1.73 \mathrm{~m}^{2}$ ), as follows:

$$
\begin{aligned}
186.3 & \times\left(\text { serum creatinine }^{-1.154}\right) \times\left(\text { age }^{-0.203}\right) \\
& \times 0.742(\text { if female }) .
\end{aligned}
$$

Comorbidities, including hypertension and dyslipidemia, were also recorded. Patients who received an antihypertensive drug for $>1$ week, except a diuretic for edema, were recorded as having hypertension. Dyslipidemia was defined based on a patient ever receiving statin therapy. Hypoglycemia was defined as a self-monitoring blood glucose level $<70 \mathrm{mg} / \mathrm{dL}$ or self-reported hypoglycemia. This study was conducted according to the guidelines of the Declaration of Helsinki, and the research protocol was approved by the Ethics Committee of the Chang Gung Memorial Hospital.

\section{Assays}

The concentrations of FPG, TC, LDL, HDL, TG, and $\mathrm{Cr}$ were measured from serum using a commercial enzymelinked immunosorbent assay kit and performed with an autoanalyzer (Hitachi 7250; Hitachi Ltd., Tokyo, Japan). Urine albumin concentrations were determined by immunonephelometry (Dade Behring Marburg GmbH, Marburg, Germany). The $\mathrm{HbA}_{1 \mathrm{c}}$ level was measured by high-pressure liquid chromatography (Bio-Rad Laboratories Inc., Hercules, CA, USA).

\section{Statistical analysis}

The variables are summarized as the mean \pm standard deviation. Differences in baseline clinical and biochemical characteristics were tested using a paired $t$-test. The repeated measures of a general linear model were used to analyze the sequential changes in $\mathrm{HbA}_{1 \mathrm{c}}$. A $P$-value $<0.05$ was considered statistically significant. All statistical operations were performed using the Statistical Package for Social Science program (SPSS for Windows, version 11.5; IBM Corporation, Armonk, NY, USA).

\section{Results}

The average duration of sitagliptin therapy for the 76 patients in the current study was $52.4 \pm 4.1$ months. All of the patients were prescribed sitagliptin monotherapy for $>48$ months. Two patients used sitagliptin for $>52$ months. Seventeen, 21 , and 38 patients received $25 \mathrm{mg} /$ day, $50 \mathrm{mg} /$ day, and $100 \mathrm{mg}$ /day of sitagliptin, respectively. The change in dose of sitagliptin during the 48-month observation period was $69.4 \pm 24.3 \mathrm{mg}$ to $67.3 \pm 23.6 \mathrm{mg}(P=0.36)$. No hypoglycemic episodes were reported.

As shown in Table 1, the change in $\mathrm{HbA}_{1 \mathrm{c}}$ from baseline was significant after 6 months and 48 months of treatment $(7.1 \% \pm 0.8 \%, 6.3 \% \pm 0.2 \%$, and $6.4 \% \pm 0.4 \%$, respectively; $P<0.01)$. Changes in baseline renal function were not apparent after 48 months of treatment $(\mathrm{Cr}$, $1.36 \pm 0.73 \mathrm{mg} / \mathrm{dL}$ and $1.32 \pm 0.67 \mathrm{mg} / \mathrm{dL}$, respectively $[P=0.20]$; eGFR, $53.4 \pm 24.3 \mathrm{~mL} /$ minute $/ 1.73 \mathrm{~m}^{2}$ and $57.6 \pm 23.0 \mathrm{~mL} / \mathrm{minute} / 1.73 \mathrm{~m}^{2}$, respectively; $P=0.36$ ). Body mass index was stable after sitagliptin monotherapy $\left(26.5 \pm 4.5 \mathrm{~kg} / \mathrm{m}^{2}\right.$ and $26.1 \pm 4.2 \mathrm{~kg} / \mathrm{m}^{2}$, respectively; $\left.P=0.45\right)$. There were no apparent changes in FPG $(123 \pm 20.1 \mathrm{mg} / \mathrm{dL}$ and $112 \pm 24.4 \mathrm{mg} / \mathrm{dL}$, respectively; $P=0.06)$, TG $(159.2 \pm 94.2 \mathrm{mg} / \mathrm{dL}$ and $161.1 \pm 111.4 \mathrm{mg} / \mathrm{dL}$, respectively; $P=0.72)$, TC $(176.5 \pm 40.5 \mathrm{mg} / \mathrm{dL}$ and $178.8 \pm 38.7 \mathrm{mg} / \mathrm{dL}$, respectively; $P=0.61)$, HDL $(47.1 \pm 12.6 \mathrm{mg} / \mathrm{dL}$ and $46.8 \pm 12.1 \mathrm{mg} / \mathrm{dL}$, respectively; $P=0.48)$, and $\mathrm{LDL}$ $(99.1 \pm 35.1 \mathrm{mg} / \mathrm{dL}$ and $100.1 \pm 31.6 \mathrm{mg} / \mathrm{dL}$, respectively; $P=0.28$ ). The prevalence of patients with hypertension and dyslipidemia did not appear to increase from the time of enrollment until the study had ended (22 versus $29, P=0.07 ; 30$ versus $33, P=0.83$, respectively). Patients received angiotensin receptor blockers or angiotensin-converting enzyme inhibitor therapy for hypertension; statin use for dyslipidemia did not increase ( 22 versus 23; 29 versus 30 ; all $P=0.32$ ). Chronic microvascular complications (retinopathy [1 versus 1] [the number 
of patient with retionapthy before and after 48 months], nephropathy [19 versus $20, P=0.40]$, and neuropathy [24 versus $25 ; P=0.34]$ ) were not significantly increased during the 48-month follow-up in our share-care program (Table 1). There were no hospital admissions for cardiovascular events during the observation period in the study group.

In the general linear model, we used repeated measures to test the sequential changes in $\mathrm{HbA}_{1 \mathrm{c}}$ from month 6 to month 48 . The test of within-subjects effect was not significant $(P=0.34$; Figure 1). We also used sex as a between-subjects factor; there were no apparent differences between the sexes $(P=0.98)$.

The patients who received different doses of sitagliptin had apparent reductions in $\mathrm{HbA}_{1 \mathrm{c}}$ from baseline during the first 6 months of treatment $(25 \mathrm{mg}, 7.3 \% \pm 1.3 \%$ and $6.0 \% \pm 0.8 \%$, respectively; $50 \mathrm{mg}, 7.1 \% \pm 0.8 \%$ and $6.3 \% \pm 0.6 \%$, respectively; and $100 \mathrm{mg}, 7.1 \% \pm 0.8 \%$ and $6.3 \% \pm 0.6 \%$, respectively; all $P<0.001$ ); the $\mathrm{HbA}_{1 \mathrm{c}}$ levels remained stable in patients receiving different doses of sitagliptin between month 6 and month 48 (Figure 2). There were no statistically significant differences in $\mathrm{HbA}_{1 \mathrm{c}}$ concentrations between sitagliptin regimens $(P=0.23$ [tests of the between-subjects effect]).

\section{Discussion}

We studied 76 drug-naïve patients who received sitagliptin monotherapy for $>48$ months. The $\mathrm{HbA}_{1 \mathrm{c}}$ level decreased significantly after 6 months of sitagliptin therapy, but the $\mathrm{HbA}_{1 \mathrm{c}}$ levels fluctuated mildly; the $\mathrm{HbA}_{1 \mathrm{c}}$ was well controlled for $>48$ months. Although the sample size was small, the durability of sitagliptin was demonstrated and there were no apparent changes in body weight, renal function, and the lipid profile. No hypoglycemic episodes were reported during monotherapy with sitagliptin. Before beginning sitagliptin therapy, all patients had already received lifestyle modification counseling, including diet education, for $>6$ months. Although neither a diet diary nor a daily activity record was maintained, lifestyle modification counseling clearly had a meaningful effect on the patients. In a review article, ${ }^{25}$ the author concluded that based on nonglycemic effects, such as the risk of hypoglycemia, weight gain, and durability, DPP-4 inhibitors may be considered an alternative to SUs, which directly stimulate pancreatic $\beta$-cells to secrete insulin. Of note, in the A Diabetes Outcome Progression Trial (ADOPT), ${ }^{26}$ the cumulative incidence of monotherapy failure at 5 years was $15 \%$ with rosiglitazone, $21 \%$ with metformin, and $34 \%$ with glyburide. Indeed, the increasing risk of cardiovascular events and bladder cancer may be of greater concern than the durability of thiazolidinediones. ${ }^{14-16}$

Williams-Herman et al ${ }^{12}$ analyzed $>10,000$ subjects in clinical trials and concluded that sitagliptin was well tolerated for as long as 2 years. The longest published study of sitagliptin monotherapy was up to 104 weeks and has been reported

Table I The clinical and biochemical characteristics of patients before and after 48 months of sitagliptin therapy

\begin{tabular}{|c|c|c|c|}
\hline & Before sitagliptin use & $\begin{array}{l}\text { After sitagliptin use } \\
\text { (48 months) }\end{array}$ & $P$-value \\
\hline Age (years) & $71.3 \pm 11.7$ & & \\
\hline Sex (male/female) & $36 / 40$ & $36 / 40$ & \\
\hline Dose (mg) & $69.4 \pm 24.4$ & $67.3 \pm 23.6$ & 0.36 \\
\hline FPG (mg/dL) & $123 \pm 20.1$ & $112 \pm 24.4$ & 0.06 \\
\hline Creatinine (mg/dL) & $1.36 \pm 0.73$ & $1.32 \pm 0.67$ & 0.20 \\
\hline eGFR (mL/minute/l.73 $\left.\mathrm{m}^{2}\right)$ & $53.4 \pm 24.3$ & $57.6 \pm 23.0$ & 0.36 \\
\hline $\mathrm{HbA}_{\mathrm{Ic}}(\%)$ & $7.1 \pm 0.8$ & $6.4 \pm 0.4$ & $<0.0001$ \\
\hline BMI $\left(\mathrm{kg} / \mathrm{m}^{2}\right)$ & $26.5 \pm 4.5$ & $26.1 \pm 4.2$ & 0.45 \\
\hline TG (mg/dL) & $159.2 \pm 94.2$ & $|6| .1 \pm 111.4$ & 0.72 \\
\hline $\mathrm{TC}(\mathrm{mg} / \mathrm{dL})$ & $176.5 \pm 40.5$ & $178.8 \pm 38.7$ & 0.61 \\
\hline $\mathrm{HDL}(\mathrm{mg} / \mathrm{dL})$ & $47.1 \pm 12.6$ & $46.8 \pm 12.2$ & 0.48 \\
\hline LDL (mg/dL) & $99.1 \pm 35.1$ & $100.1 \pm 31.6$ & 0.28 \\
\hline \multicolumn{4}{|l|}{ Comorbidities (number) } \\
\hline Hypertension & 22 & 29 & 0.07 \\
\hline ARB or ACEI & 22 & 23 & 0.32 \\
\hline Dyslipidemia & 30 & 33 & 0.83 \\
\hline Statin & 29 & 30 & 0.32 \\
\hline Retinopathy & 1 & 1 & - \\
\hline Neuropathy & 24 & 25 & 0.34 \\
\hline Nephropathy & 19 & 20 & 0.40 \\
\hline
\end{tabular}

Abbreviations: FPG, fasting plasma glucose; eGFR, estimated glomerular filtration rate; HbA ${ }_{I c}$, glycated hemoglobin; BMI, body mass index; TG, triglycerides; TC, total cholesterol; HDL, high-density lipoprotein; LDL, low-density lipoprotein; ARB, angiotensin receptor blocker; ACEl, angiotensin-converting enzyme inhibitor. 


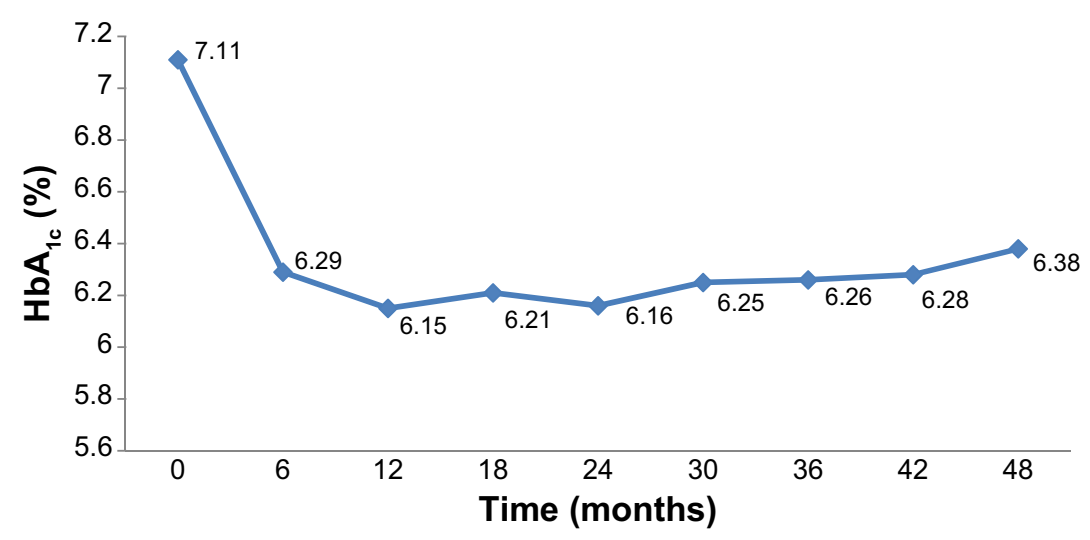

Figure I Change in the $\mathrm{HbA}_{1 \mathrm{c}}$ levels from baseline at 6-month intervals.

Abbreviation: $\mathrm{HbA}_{\mathrm{Ic}}$, glycated hemoglobin.

by Williams-Herman et $\mathrm{al}^{28}$ (American Diabetes Association 2009 , abstract 540P) in which the $\mathrm{HbA}_{1 \mathrm{c}}$ decreased from $8.5 \%$ to $7.4 \%$ in 50 patients. In a review article involving published randomized, double-blind studies in patients with inadequately controlled $\mathrm{T} 2 \mathrm{DM}\left(\mathrm{HbA}_{1 \mathrm{c}}=6.5 \%-10 \%\right)$, the studies were only $12-24$ weeks in length. ${ }^{28}$ The reductions in baseline $\mathrm{HbA}_{1 \mathrm{c}}$ ranged from $0.48 \%-0.70 \%$ among patients randomized to receive sitagliptin (all $P<0.001$ ). In the present study, the enrolled patients did not have higher $\mathrm{HbA}_{1 \mathrm{c}}$ concentrations $(6.3 \%-7.9 \%)$ when compared to the 2 -year study of Williams-Herman et $\mathrm{al}^{27}$ because we followed a previous study involving sitagliptin monotherapy, in which the $\mathrm{HbA}_{1 \mathrm{c}}$ concentration was lowered by $0.6 \%-0.7 \%$ and the patients had a target $\mathrm{HbA}_{1 \mathrm{c}}$ of $6.5 \%-7 \% .{ }^{28}$ In the initial 6 months of therapy, the $\mathrm{HbA}_{1 \mathrm{c}}$ concentration was reduced by approximately $0.8 \%$ in the current study, followed by a $0.1 \%$ increase from 6 months to 48 months of sitagliptin therapy. We also showed that a different dose of sitagliptin had the same $\mathrm{HbA}_{1 \mathrm{c}}$-lowering effect, and that there was no statistically significant difference in the $\mathrm{HbA}_{1 \mathrm{c}}$ concentration between sitagliptin regimens. The patients enrolled in our study were all elderly and at higher risk for developing ischemic heart disease, congestive heart failure, and age-related nephropathy. Hypoglycemia may be a sequential problem or factor precipitating these complications. According to a previous study, sitagliptin has a lower risk of hypoglycemia and a better safety profile in elderly patients. ${ }^{29}$ Generally, metformin, GLP-1 analogs/DPP-4 inhibitors, and long-acting insulin are preferred over other treatment options (SU, glinides, and glitazones) in older patients. ${ }^{29}$ The cardiovascular safety of DPP-4 inhibitors has also been reported in two recent large clinical trials. ${ }^{3,4}$ In an open-label, randomized study involving elderly patients in Taiwan, Chien et $\mathrm{al}^{31}$ reported that 24 weeks of sitagliptin produced a reduction

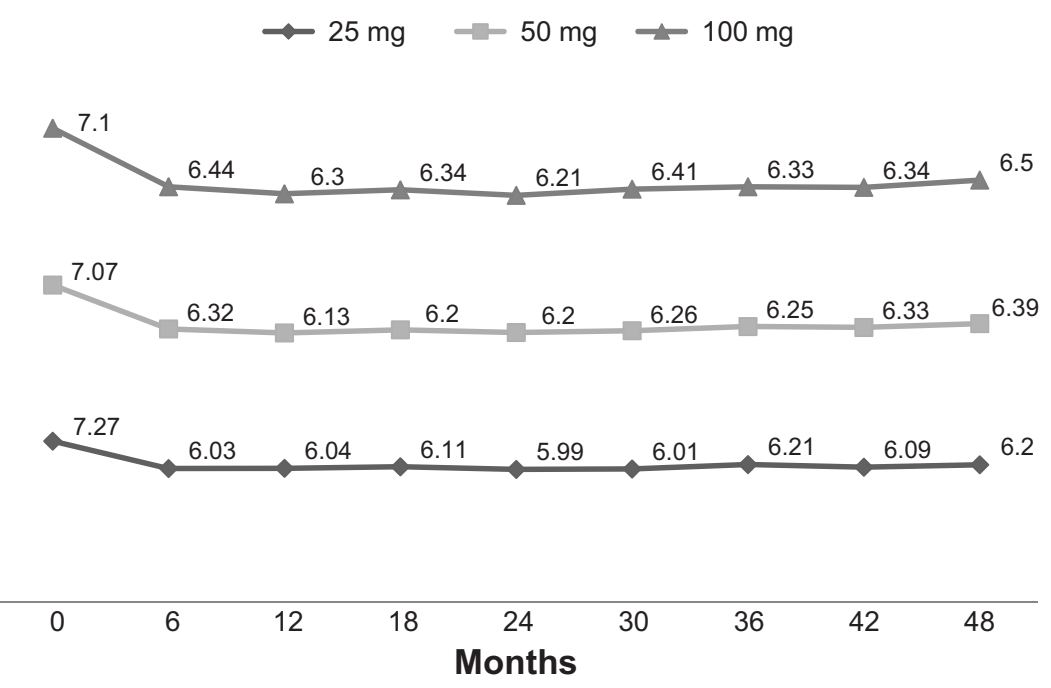

Figure 2 Change in $\mathrm{HbA}_{\mathrm{Ic}}$ levels as a function of sitagliptin dose.

Notes: The patients who received different doses of sitagliptin had apparent reductions in $\mathrm{HbA}_{\mathrm{lc}}$ from baseline during the first 6 months of treatment. The $\mathrm{HbA}$ levels remained stable in patients receiving different doses of sitagliptin between month 6 and month 48 .

Abbreviation: $\mathrm{HbA}_{\mathrm{lc}}$, glycated hemoglobin. 
in the $\mathrm{HbA}_{1 \mathrm{c}}$ concentration of $1.3 \%$ from a baseline average $\mathrm{HbA}_{1 \mathrm{c}}$ of $9.5 \%$ compared with the control group. The elderly patients are more likely to have age-related kidney problems, which may require an adjustment in the dose for patients receiving sitagliptin. In the current study, the average eGFR was $<60 \mathrm{~mL} /$ minute $/ 1.73 \mathrm{~m}^{2}$ and the dose of sitagliptin was $<70 \mathrm{mg}$.

Despite only 4 years of observation, chronic microvascular complications (retinopathy, nephropathy, and neuropathy) were evaluated every year, and were not increased in the current study. The changes in antihypertensive and statin treatments were also not apparent before or after 4 years of sitagliptin therapy. In an animal study, ${ }^{32}$ DPP-4 inhibitors in combination with angiotensin II receptor blocker treatment significantly reduced urinary albumin excretion and oxidative stress in diabetic endothelial nitric oxide synthase knockout mice and offered a new therapeutic approach for patients with diabetic nephropathy. ${ }^{32}$ In a large-scale clinical trial involving saxagliptin and cardiovascular outcomes in patients with T2DM, a decrease in microalbuminuria was reported. ${ }^{2}$ Functional GLP-1R expressed in retinal pigment epithelium cells also revealed the potential direct beneficial effects of GLP-1 treatment or an increase in GLP-1 via a DPP-4 inhibitor against diabetic retinopathy. ${ }^{33}$ A long-acting DPP-4 inhibitor (vildagliptin analog), when used in streptozotocininduced diabetic peripheral neuropathy, can improve nerve function by preventing, blocking, or counteracting the progression of peripheral neuropathy in experimental diabetic rats. ${ }^{34}$ Therefore, sitagliptin may decrease the progression of microvascular complications.

There were several limitations to this study. First, 4 years of observations is inadequate to assess chronic complications; further long-term evaluation is indicated. Second, because of the age of the patients, age-related nephropathy cannot be ruled out. Although only one patient developed retinopathy, we cannot diagnose "diabetic nephropathy". We used "nephropathy" to present the changes in kidney complications. Third, the sample size was small, so a further large-scale study may be needed.

\section{Conclusion}

This study has revealed the endurance of sitagliptin in elderly patients with T2DM. Glycemic control improved significantly, even in patients with a lower baseline $\mathrm{HbA}_{1 \mathrm{c}}$ concentration, and the progression of microvascular complications stabilized, with sustained effects as long as 4 years. Long-term observation is indicated for these patients. This study can provide useful data for clinicians and health care professionals using sitagliptin monotherapy in the treatment of elderly patients with T2DM.

\section{Disclosure}

The authors report no conflicts of interest in this work.

\section{References}

1. Turner RC, Cull CA, Frighi V, Holman RR. Glycemic control with diet, sulfonylurea, metformin, or insulin in patients with type 2 diabetes mellitus: progressive requirement for multiple therapies (UKPDS 49). UK Prospective Diabetes Study (UKPDS) Group. JAMA. 1999;281(21):2005-2012.

2. Inzucchi SE1, Bergenstal RM, Buse JB, et al; American Diabetes Association (ADA); European Association for the Study of Diabetes (EASD). Management of hyperglycemia in type 2 diabetes: a patient-centered approach: position statement of the American Diabetes Association (ADA) and the European Association for the Study of Diabetes (EASD). Diabetes Care. 2012;35(6):1364-1379.

3. Scirica BM, Bhatt DL, Braunwald E, et al; SAVOR-TIMI 53 Steering Committee and Investigators. Saxagliptin and cardiovascular outcomes in patients with type 2 diabetes mellitus. N Engl J Med. 2013;369(14): 1317-1326.

4. White WB, Cannon CP, Heller SR, et al; EXAMINE Investigators. Alogliptin after acute coronary syndrome in patients with type 2 diabetes. N Engl J Med. 2013;369(14):1327-1335.

5. Herman GA, Stein PP, Thornberry NA, Wagner JA. Dipeptidyl peptidase- 4 inhibitors for the treatment of type 2 diabetes: focus on sitagliptin. Clin Pharmacol Ther. 2007;81(5):761-767.

6. Gallwitz B. Sitagliptin: profile of a novel DPP-4 inhibitor for the treatment of type 2 diabetes. Drugs Today (Barc). 2007;43(1):13-25.

7. Aschner P, Katzeff HL, Guo H, et al; Sitagliptin Study 049 Group. Efficacy and safety of monotherapy of sitagliptin compared with metformin in patients with type 2 diabetes. Diabetes Obes Metab. 2010;12(3):252-261.

8. Karasik A, Aschner P, Katzeff H, Davies MJ, Stein PP. Sitagliptin, a DPP-4 inhibitor for the treatment of patients with type 2 diabetes: a review of recent clinical trials. Curr Med Res Opin. 2008;24(2): 489-496.

9. Florentin M, Liberopoulos EN, Mikhailidis DP, Elisaf MS. Sitagliptin in clinical practice: a new approach in the treatment of type 2 diabetes. Expert Opin Pharmacother. 2008;9(10):1705-1720.

10. Iwamoto Y, Tajima N, Kadowaki T, et al. Efficacy and safety of sitagliptin monotherapy compared with voglibose in Japanese patients with type 2 diabetes: a randomized, double-blind trial. Diabetes Obes Metab. 2010;12(7):613-622.

11. Seck T, Nauck M, Sheng D, et al; Sitagliptin Study 024 Group. Safety and efficacy of treatment with sitagliptin or glipizide in patients with type 2 diabetes inadequately controlled on metformin: a 2-year study. Int J Clin Pract. 2010;64(5):562-576.

12. Williams-Herman D, Engel SS, Round E, et al. Safety and tolerability of sitagliptin in clinical studies: a pooled analysis of data from 10,246 patients with type 2 diabetes. BMC Endocr Disord. 2010;10:7.

13. Lai MS, Chu CS, Lin SH, Lin MS. Prescribing patterns in primary health care in Taiwan. Int J Clin Pharmacol Ther. 1995;33(8):437-441.

14. Nissen SE, Wolski K. Effect of rosiglitazone on the risk of myocardial infarction and death from cardiovascular causes. N Engl J Med. 2007; 356(24):2457-2471.

15. Azoulay L, Yin H, Filion KB, et al. The use of pioglitazone and the risk of bladder cancer in people with type 2 diabetes: nested case-control study. BMJ. 2012;344:e3645.

16. Lewis JD, Ferrara A, Peng T, et al. Risk of bladder cancer among diabetic patients treated with pioglitazone: interim report of a longitudinal cohort study. Diabetes Care. 2011;34(4):916-922.

17. Round EM, Engel SS, Golm GT, Davies MJ, Kaufman KD, Goldstein BJ. Safety of sitagliptin in elderly patients with type 2 diabetes: a pooled analysis of 25 clinical studies. Drugs Aging. 2014;31(3):203-214. 
18. Mu J, Woods J, Zhou YP, et al. Chronic inhibition of dipeptidyl peptidase-4 with a sitagliptin analog preserves pancreatic beta-cell mass and function in a rodent model of type 2 diabetes. Diabetes. 2006;55(6):1695-1704.

19. Liniger C, Albeanu A, Bloise D, Assal JP. The tuning fork revisited. Diabet Med. 1990;7(10):859-864.

20. Mythili A, Kumar KD, Subrahmanyam KA, Venkateswarlu K, Butchi RG. A comparative study of examination scores and quantitative sensory testing in diagnosis of diabetic polyneuropathy. Int J Diabetes Dev Ctries. 2010;30(1):43-48.

21. Lee S, Kim H, Choi S, Park Y, Kim Y, Cho B. Clinical usefulness of the two-site Semmes-Weinstein monofilament test for detecting diabetic peripheral neuropathy. J Korean Med Sci. 2003;18(1):103-107.

22. American Academy of Ophthalmology Retina/Vitreous Panel; Preferred Practice Patterns Committee. Diabetic Retinopathy. San Francisco, CA: American Academy of Ophthalmology (AAO); 2008.

23. Lopez-Bastida J, Cabrera-Lopez F, Serrano-Aguilar P. Sensitivity and specificity of digital retinal imaging for screening diabetic retinopathy. Diabet Med. 2007;24(4):403-407.

24. Brownlee M, Aiello LP, Cooper ME, Vinik AI, Nesto RW, Boulton AJM. Complications of diabetes mellitus. In: Melmed S, Polonsky K, Larsen PR, Kronenberg KM, editors. Williams Textbook of Endocrinology. 12th ed. Philadelphia: Saunders (Elsevier); 2011:1462-551.

25. Davidson JA. The placement of DPP-4 inhibitors in clinical practice recommendations for the treatment of type 2 diabetes. Endocr Pract. 2013;19(6):1050-1061.
26. Kahn SE, Haffner SM, Heise MA, et al; ADOPT Study Group. Glycemic durability of rosiglitazone, metformin, or glyburide monotherapy. N Engl J Med. 2006;355(23):2427-2443.

27. Williams-Herman D, Johnson J, Teng R, et al. Amatruda JM.Efficacy and safety of sitagliptin and metformin as initial combination therapy and as monotherapy over 2 years in patients with type 2 diabetes. Diabetes Obes Metab. 2010;12(5):442-451.

28. Plosker GL. Sitagliptin: a review of its use in patients with type 2 diabetes mellitus. Drugs. 2014;74(2):223-242.

29. Kim W, Egan JM. The role of incretins in glucose homeostasis and diabetes treatment. Pharmacol Rev. 2008;60(4):470-512.

30. Tschöpe D, Hanefeld M, Meier JJ, et al. The role of co-morbidity in the selection of antidiabetic pharmacotherapy in type-2 diabetes. Cardiovasc Diabetol. 2013;12:62.

31. Chien MN, Lee CC, Chen WC, Liu SC, Leung CH, Wang CH. Effect of sitagliptin as add-on therapy in elderly type 2 diabetes patients with inadequate glycemic control in Taiwan. Int J Gerontol. 2011;5(2):103-106.

32. Alter ML, Ott IM, von Websky K, et al. DPP-4 inhibition on top of angiotensin receptor blockade offers a new therapeutic approach for diabetic nephropathy. Kidney Blood Press Res. 2012;36(1):119-130.

33. Puddu A, Sanguineti R, Montecucco F, Viviani GL. Retinal pigment epithelial cells express a functional receptor for glucagon-like peptide-1 (GLP-1). Mediators Inflamm. 2013;2013:975032.

34. Bianchi R, Cervellini I, Porretta-Serapiglia C, et al. Beneficial effects of PKF275-055, a novel, selective, orally bioavailable, long-acting dipeptidyl peptidase IV inhibitor in streptozotocin-induced diabetic peripheral neuropathy. J Pharmacol Exp Ther. 2012;340(1):64-72.
Clinical Interventions in Aging

\section{Publish your work in this journal}

Clinical Interventions in Aging is an international, peer-reviewed journal focusing on evidence-based reports on the value or lack thereof of treatments intended to prevent or delay the onset of maladaptive correlates of aging in human beings. This journal is indexed on PubMed Central, MedLine,

\section{Dovepress}

CAS, Scopus and the Elsevier Bibliographic databases. The manuscript management system is completely online and includes a very quick and fair peer-review system, which is all easy to use. Visit http://www.dovepress. com/testimonials.php to read real quotes from published authors. 